\title{
Article \\ A Miniaturized FSS-Based Eight-Element MIMO Antenna Array for Off/On-Body WBAN Telemetry Applications
}

\author{
Muhammad Bilal ${ }^{1, *(\mathbb{D}}$, Sara Shahid ${ }^{2}$, Yousuf Khan ${ }^{3}$, Zahid Rauf ${ }^{1} \mathbb{D}$, Raja A. Wagan ${ }^{4}$, Muhammad A. Butt ${ }^{5,6} \mathbb{D}$, \\ Svetlana N. Khonina ${ }^{6,7}$ (D) and Nikolay L. Kazanskiy ${ }^{6,7}$ (D)
}

\section{check for} updates

Citation: Bilal, M.; Shahid, S.; Khan, Y.; Rauf, Z.; Wagan, R.A.; Butt, M.A.; Khonina, S.N.; Kazanskiy, N.L. A Miniaturized FSS-Based EightElement MIMO Antenna Array for Off/On-Body WBAN Telemetry Applications. Electronics 2022, 11, 522. https://doi.org/10.3390/ electronics11040522

Academic Editor: Manuel

Felipe Cátedra Pérez

Received: 27 November 2021

Accepted: 7 February 2022

Published: 10 February 2022

Publisher's Note: MDPI stays neutral with regard to jurisdictional claims in published maps and institutional affiliations.

Copyright: (c) 2022 by the authors. Licensee MDPI, Basel, Switzerland. This article is an open access article distributed under the terms and conditions of the Creative Commons Attribution (CC BY) license (https:// creativecommons.org/licenses/by/ $4.0 /)$.
1 Microwaves, Antennas and Propagation Research Group, Department of Telecommunication Engineering, Balochistan University of IT, Engineering and Management Sciences, Quetta 87300, Pakistan; zahid.rauf@buitms.edu.pk

2 Trainee Engineer Huawei, Quetta 87300, Pakistan; sara.buitems@gmail.com

3 Department of Electronic Engineering, Balochistan University of IT, Engineering and Management Sciences, Quetta 87300, Pakistan; yousuf.naudhani@gmail.com

4 Department of Information Technology, Balochistan University of IT, Engineering and Management Sciences, Quetta 87300, Pakistan; raja.asif@buitms.edu.pk

5 Institute of Microelectronics and Optoelectronics, Warsaw University of Technology, Koszykowa 75, 00-662 Warszawa, Poland; butt.m@ssau.ru

6 Department of Technical Cybernetics, Samara National Research University, 443086 Samara, Russia; khonina@ipsiras.ru (S.N.K.); kazanskiy@ipsiras.ru (N.L.K.)

7 IPSI RAS-Branch of the FSRC "Crystallography and Photonics" RAS, 443001 Samara, Russia

* Correspondence: muhammad.bilal4@buitms.edu.pk

\begin{abstract}
In this paper, a compact multiple-input multiple-output (MIMO) antenna for an off/onbody wireless body area network (WBAN) is presented. The proposed antenna comprises eight elements arranged in a side-by-side, orthogonal, and across configuration on a planar laminate. This MIMO system achieves wideband impedance matching, i.e., fractional bandwidth (FBW) $=111 \%$ $(7600 \mathrm{MHz})$ when placed off-body and FBW $=110 \%(7500 \mathrm{MHz})$ when placed on-body. The achieved bandwidth covers the ultrawideband (UWB) ranges 3.1-10.6 GHz for UWB-WBANs. To isolate the antenna elements, a Jerusalem cross (JC)-shaped frequency-selective surface (FSS) and meandered structure (MS) was designed and optimized. This proposed isolation mechanism offers at least $20 \mathrm{~dB}$ of isolation while maintaining an overall compact profile. Moreover, MIMO performance parameters for off/on-body and the specific absorption rate (SAR) were also evaluated. Stable MIMO performance, acceptable limits of SAR, and optimum radiation characteristics verify its suitability for wideband biotelemetry applications.
\end{abstract}

Keywords: antenna array; frequency-selective surfaces (FSS); wireless body-area networks (WBAN); specific absorption rate (SAR)

\section{Introduction}

Wireless body area networks are an emerging technology that has gained attention from researchers because of their applications in the field of healthcare for children, the elderly [1,2], military, and sports. WBANs are linked with devices such as actuators or sensors that are implanted inside or on the human body [3]. Usually extended over the whole human body, these devices communicate with this body area network (BAN) through a wireless link to monitor conditions of patients such as heart rate, pulse rate, blood pressure, and blood flow. WBAN telemetry assesses the human body condition and shares this bio-information with an external monitoring source over a distance for evaluation and diagnosis. The on-body antenna is an essential part of this bio-telemetric communication [4]. This approach aims to enable a shift from symptom-based medication to a proactive healthcare system. 
Ultrawideband (UWB) technology is an attractive technology for these WBAN telemetry applications due to its features such as higher data rates over short-range communication and much larger bandwidth from 3.1 to $10.6 \mathrm{GHz}[5,6]$. Designing WBAN antennas is challenging, especially for wideband operations such as UWB. Considering its design, the coupling effect of the antenna with the human body is a critical factor, which is considered first. Another challenge is to maintain the low cost, compactness, mechanical stability, light weight, ease of fabrication, flexibility, and comfort for users/consumers $[7,8]$. These antennas operate in proximity of any body tissues, and their radiation is affected by different body parts [9-11]. Hence, another aspect that needs to be considered is the specific absorption rate (SAR) while designing such antennas [12].

Numerous UWB antennas for WBAN applications are reported in the existing literature. A mono-cone UWB antenna for WBAN was presented in [13]. This complex threedimensional design was printed on a planar laminate having a dimension of $80 \mathrm{~mm} \times 80 \mathrm{~mm}$ ground plane and $0.05 \lambda_{\mathrm{o}}$ height with wideband impedance matching up to $24 \mathrm{GHz}$. A UWBWBAN directional antenna was presented in [14]. The design comprised a funnel-shaped antenna and a fork slotted EBG structure at the ground plane. The design achieved impedance matching for the complete UWB both in free space and on the body over $20 \mathrm{~mm} \times 25 \mathrm{~mm}$ dimensions. In [15], UWB radio channel characteristics were studied in between capsule endoscopy and a directive body antenna. Capsule endoscopy is used for the examination of the lower abdomen, especially for the gastrointestinal tract. A miniaturized dipole antenna having dimensions of $11 \mathrm{~mm} \times 25 \mathrm{~mm}$ was placed inside the capsule, which offers very limited bandwidth for on-body operations.

A dual open-ring antenna with triple resonant bands for wearable application was reported in [16]. The antenna system comprised two layers, a rigid and a textile substrate. On-body results were achieved over three-layered human tissue models having $160 \mathrm{~mm} \times 160 \mathrm{~mm}$ dimensions. This reported design offered very limited impedance matching up to 2-4 GHz. In [17], a wideband antenna for wearable biotelemetry applications was presented. The design comprised a rectangular-shaped antenna with two vertical slits and a semi hook-shaped ground. It provided limited impedance matching in free space and on the body with overall dimensions of $17 \mathrm{~mm} \times 25 \mathrm{~mm}$. An L-shaped antenna having a coplanar waveguide (CPW) feed with a metallic back reflector was reported in [18]. The design provided dual-band operation at $2.45 / 5.8 \mathrm{GHz}$ with $20 \mathrm{~dB}$ impedance matching for both flat and flexible configurations having overall dimensions of $30 \mathrm{~mm} \times 31 \mathrm{~mm}$. In [19], an I-shaped monopole dual-band antenna for wearable applications was presented. The design used an I-shaped radiator with an inverted L-shaped slit etched and an inverted U-shaped ground, providing a $20 \mathrm{~dB}$ impedance match for dual band over $19 \mathrm{~mm} \times 12 \mathrm{~mm}$ dimensions. In [20], a circular monopole antenna for wearable applications was presented. A conventional circular monopole with rectangular ring electromagnetic bandgap (EBG) structures provided impedance matching ranges from $2.4 \mathrm{GHz}$ to $6.5 \mathrm{GHz}$ over larger dimensions of $69 \mathrm{~mm} \times 69 \mathrm{~mm}$.

In [21], a miniaturized textile-based circularly polarized antenna having dimensions of $25 \mathrm{~mm} \times 30 \mathrm{~mm}$ was reported. This antenna had a single feeding mechanism that achieved impedance matching ranges up to 3.09-11 GHz through the incorporation of a tapered L-shaped ground and cross-shaped stub in the main radiation element. A textile-based four-port circularly polarized and wideband MIMO antenna system having dimensions of $32.5 \mathrm{~mm} \times 42 \mathrm{~mm}$ was presented in [22]. These sickle-shaped antennas having an L-shaped ground plane achieved 3-13 GHz of wideband impedance matching for wearable applications. A dual-polarized step-shaped monopole and an irregular rectangular loop antenna having a conformal profile were designed for ingestible wireless capsule endoscope (WCE) systems in [23]. They achieved a wide impedance bandwidth of 2.15-14.75 GHz over a single ported $18 \mathrm{~mm} \times 18 \mathrm{~mm}$ profile.

It may be inferred from the reported literature that these systems require compactness, low design profile, simplicity, and acceptable performance when placed on the body. In addition to this, wide bandwidth and higher data rates are also desired for modern 
biomedical communications. MIMO antenna systems can be designed to meet higher data rates [24]. However, to achieve compactness, the antennas are closely packed in MIMO systems, which raises the undesirable mutual coupling effect and, therefore, degrades the system's performance. The coupling effect can be reduced by designing and optimizing a decoupling mechanism.

The contributions of this study were as follows:

- An eight-element MIMO antenna having wider bandwidth is proposed for off/onbody (OB) WBANs.

- This antenna system maintains a wideband response of $7600 \mathrm{MHz}$ and $7500 \mathrm{MHz}$ for off- and on-body communication scenarios respectively.

- $\quad$ Antennas in side-by-side (ant. 2,3; ant 4,5; ant. 6,7; ant. 8,1) orthogonal (ant. 1,2; ant. 3,4, ant. 5,6; ant. 7,8), and across (ant. 2,7; ant 3,6) arrangements of the proposed eight-element MIMO enable achieving higher data rates without significant losses.

- The mutual coupling effect is reduced by at least $20 \mathrm{~dB}$ by incorporating two distinct isolation structures featuring an FSS-based Jerusalem cross (JC) and meandered structure (MS) for orthogonally and side-by-side/across placed antennas, respectively.

- $\quad$ The MIMO performance and SAR at $3.5 \mathrm{GHz}$ and $5 \mathrm{GHz}$ are also investigated to confirm its suitability for on-body WBAN telemetry communications.

Overall, the novelty aspect of the proposed work not only includes comprehensive design and analysis of a compact wideband MIMO antenna system for off/on-body WBANs, but also includes the following:

- Wideband antenna design with several bandwidth enhancement techniques.

- Increased number of ports in three possible configurations for high-date-rate MIMO operations.

- Wide fractional bandwidth for off/on-body scenarios.

- $\quad$ Single-layered planar configuration for biotelemetry devices.

- $\quad$ Periodic structure-based distinct isolation mechanism for all configurations.

- Low-cost fabrication and low-profile laminate along with good agreement between simulations and measurements while maintaining an efficient off- and onbody performance.

- $\quad$ Safe for on-body usage with acceptable gain and efficiency.

The novelty of the proposed work is also highlighted in comparison with the recent literature.

The remainder of the paper is organized as follows: in Section 2, the design methodology, geometrical configuration, and analysis of decoupling structures are discussed. Simulations and measurements including S-parameters, surface current distribution, radiation characteristics, MIMO performance parameters, and specific absorption rate (SAR) are presented in Section 3. A detailed discussion on the comparison with the recently reported literature is presented in Section 4. Finally, the conclusion is provided in Section 5.

\section{Design Methodology and Configuration}

\subsection{MIMO Antenna Pair}

The proposed MIMO antenna pair was designed and simulated over a low profile and readily available $1.5 \mathrm{~mm}$ thick FR-4 dielectric having compact dimensions of $45 \mathrm{~mm} \times 45 \mathrm{~mm}$. This dielectric had a relative permittivity $\varepsilon=4.4$ and dielectric loss $\operatorname{tangent} \tan \delta=0.02$. There are several perturbed antenna design variations involved in designing a rectangular patch antenna to a desired wideband MIMO design. However, the perturbed design and their optimizations are summarized into four major steps, as shown in Figure 1a. The summarized design evolution outlines the major design steps and techniques, as well as their effects. 


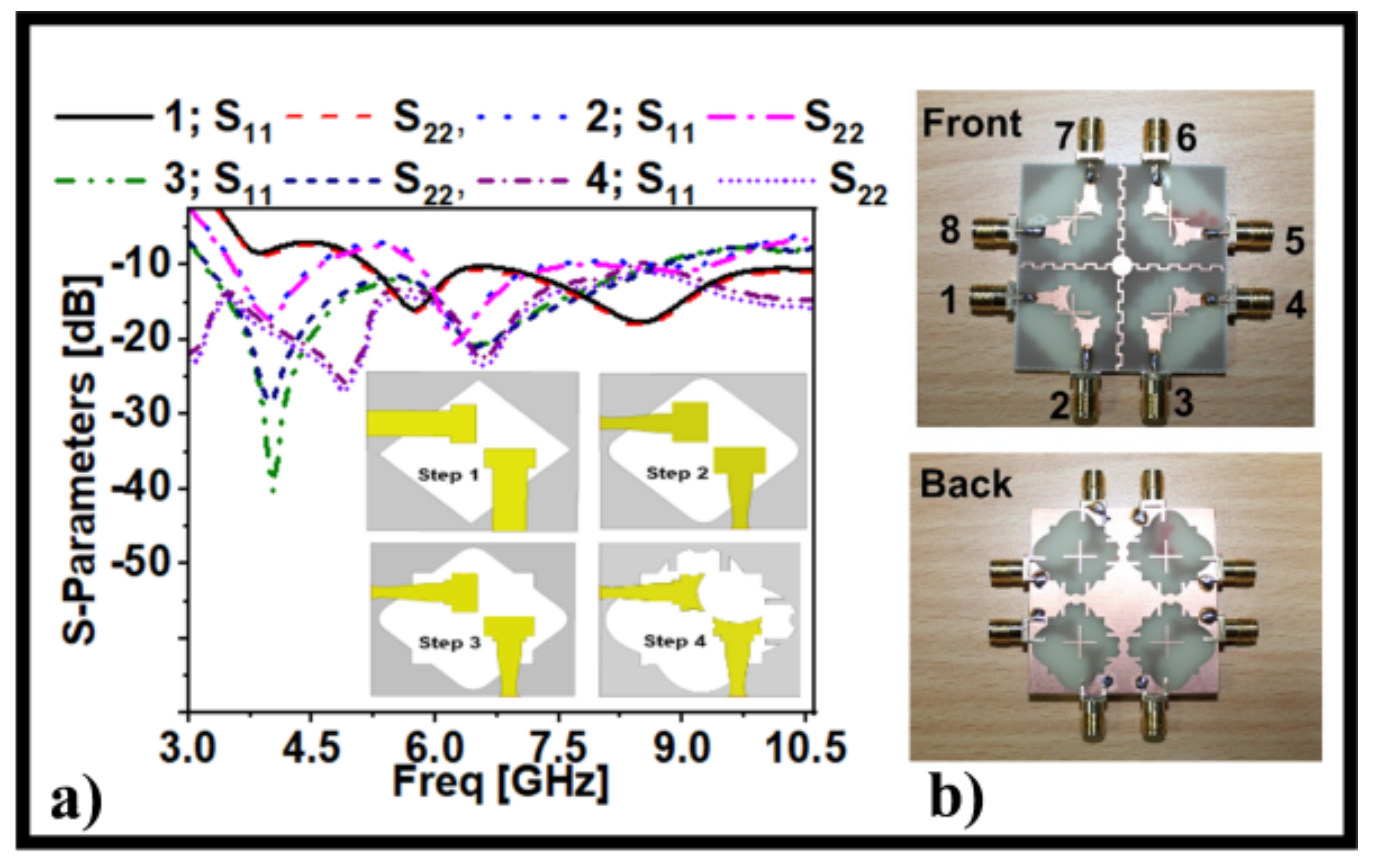

Figure 1. Design methodology and fabrications: (a) step-by-step design evolution; (b) fabricated view $($ top $=$ front side; bottom $=$ back side).

In step 1, rectangular patch antennas were designed by employing basic patch antenna design equations expressed in [25]. The antennas were initially designed at $6 \mathrm{GHz}$ and were placed orthogonally to one another having square-shaped shared grounding. The shared grounding also achieved impedance matching over higher frequencies, i.e., $6 \mathrm{GHz}$ to $8.8 \mathrm{GHz}$.

There are a number of bandwidth enhancement techniques are available in the reported literature [26]. In step 2, bandwidth enhancement techniques including beveling of feed and smooth curved ground were then applied to achieve the impedance bandwidth at lower frequency band. However, this impedance matching needed to be further improved so that losses of the isolation structures could also be compensated for in the decoupling phase.

In step 3, a staircase profiling as a lower band impedance enhancement technique was then introduced near the main radiation element to achieve a resonant response at $3.5 \mathrm{GHz}$. To balance out the effect at higher frequencies, sharp cut-based slotting was introduced in the ground to improve the resonance at higher frequencies.

Finally, step 4 introduced circular arcs and slotting in the main radiation and ground to make the current distribution more even. The impedance bandwidth at lower and higher frequencies was further enhanced. The proposed orthogonally placed MIMO pair offered a wideband impedance bandwidth of $3 \mathrm{GHz}$ to $10.6 \mathrm{GHz}$. The front and rear views of the finalized design configuration are illustrated in Figure $1 \mathrm{~b}$.

The overall dimensions of the proposed antenna were $45 \mathrm{~mm} \times 45 \mathrm{~mm}$. The optimum dimensions with respect to desired bandwidth were selected by the rigorous design parametric evaluations and analysis of the radiator, ground, meander structure, and Jerusalem cross in Ansys Electronics Desktop. The antenna design parameters were investigated from the matching and mismatching of impedance bandwidth at different frequency bands from 3-10.6 GHz. Table 1 lists the design parameters along with their effect on the bandwidth response. 
Table 1. Optimization of the proposed antenna.

\begin{tabular}{|c|c|c|c|c|c|}
\hline \multirow[t]{2}{*}{ Structures } & \multirow[t]{2}{*}{ Variables } & \multirow[t]{2}{*}{ Range (mm) } & \multirow[t]{2}{*}{ Opt. Dimension (mm) } & \multicolumn{2}{|c|}{ Impedance Bandwidth at Opt. Dimension $(\mathrm{GHz})$} \\
\hline & & & & Match & Mismatch \\
\hline \multirow{14}{*}{ Radiator } & $W_{1}$ & $1.8-2.5$ & 2.2 & $6-10.6$ & $3-6$ \\
\hline & $W_{2}$ & $2.3-3$ & 2.7 & $6-10.6$ & $3-6$ \\
\hline & $L_{1}$ & $0.5-1.5$ & 1 & $5-10.6$ & $3-5$ \\
\hline & $L_{2}$ & $1-3$ & 2.7 & $5-10.6$ & $3-5$ \\
\hline & $L_{3}$ & $7.5-8.5$ & 8.1 & $4-8.5$ & $3-4,8.5-10.6$ \\
\hline & $r_{1}$ & $4.5-5.5$ & 5.4 & $4-8.5$ & $3-4,8.5-10.6$ \\
\hline & $r_{3}$ & $8-10$ & 9.9 & 5-10.6 & $3-5$ \\
\hline & $r_{6}$ & $8.5-10$ & 9.7 & 5-10.6 & $3-5$ \\
\hline & $r_{4}$ & $1.5-3.5$ & 2.2 & $4-9$ & $3-4,9-10.6$ \\
\hline & $r_{5}$ & $2-4$ & 3 & $3.8-9$ & $3-3.8,9-10.6$ \\
\hline & $W_{5}$ & $1-2$ & 1.8 & $3.8-9$ & $3-3.8,9-10.6$ \\
\hline & $W_{7}$ & $1-3$ & 2 & $3.6-9.3$ & $3-3.6,9.3-10.6$ \\
\hline & $W_{6}$ & $1.5-3.5$ & 2.5 & $3.3-10$ & $3-3.3,10-10.6$ \\
\hline & $L_{6}$ & $0.8-1$ & 0.9 & $3.3-10$ & $3-3.3,10-10.6$ \\
\hline Ground & $L_{7}$ & $1-1.5$ & 1.2 & $3-10.6$ & - \\
\hline \multirow[t]{4}{*}{$\mathrm{JC}$} & $L_{5}$ & $7.5-8.5$ & 8.1 & $3-5,7-10.6$ & $5-7$ \\
\hline & $W_{4}$ & $0.1-0.5$ & 0.35 & $3-5,7-10.6$ & $5-7$ \\
\hline & $g_{1}$ & $6.5-8.5$ & 7.6 & $3-6,6.5-10.6$ & $6-6.5$ \\
\hline & $g_{2}$ & $6.5-8$ & 7.4 & $3-10.6$ & - \\
\hline \multirow{3}{*}{ MS } & $L_{4}$ & $0.3-5.5$ & 0.45 & $3-9.5$ & $9.5-10.6$ \\
\hline & $W_{3}$ & $2-3$ & 2.7 & $3-10$ & $10-10.6$ \\
\hline & $r_{2}$ & $3.5-5$ & 4.4 & $3-10.6$ & - \\
\hline
\end{tabular}

\subsection{Decoupling of MIMO Antenna Pair}

The proposed design suffered from coupling in three regions i.e., side-by-side, orthogonal, and across. To isolate these regions, two distinct isolation mechanisms were designed and optimized as shown in Figure 2a,b. The meandered structure (MS) was initially designed by employing a microstrip line calculated at the initial frequency, i.e., $3.5 \mathrm{GHz}$ with characteristic impedance $Z_{0}=50 \Omega$ [27]. The initial approximated length and width were evaluated to be $11.7 \mathrm{~mm} \times 2 \mathrm{~mm}$. These meandered structures were then extended to all four sides in between the side-by-side and across antenna pairs and optimized to achieve the desired bandwidth and isolation. The other significant source of mutual coupling came from orthogonal antenna pairs. To suppress this mutual coupling, an FSS-based JC was introduced to isolate the antenna pairs. This JC was placed over the top and rear end of the laminate between orthogonally placed antennas.

\subsection{Design and Analysis of FSS-Based JC}

The FSS-based JC was created by combining dual-dipole sections placed orthogonally to each other [28]. The design and analysis of the proposed JC are illustrated in Figure 3. The JC was simulated by placing it over the top and rear side of the laminate. It was then enclosed in an airbox with Perfect-E and Perfect-H boundary conditions in combination with the wave port excitations, as shown in Figure 3a. It may also be observed from the parametric variations in Figure $3 b$ that the reflection shifted to higher frequencies with a reduction in the length and width of the JC. Overall, this structure was tuned to achieve up to $27 \mathrm{~dB}$ reflectance at a center of $6.2 \mathrm{GHz}$. FSS-based decoupling structures are lossy [29]. The impedance matching was slightly reduced when JC was introduced between antenna pairs. 


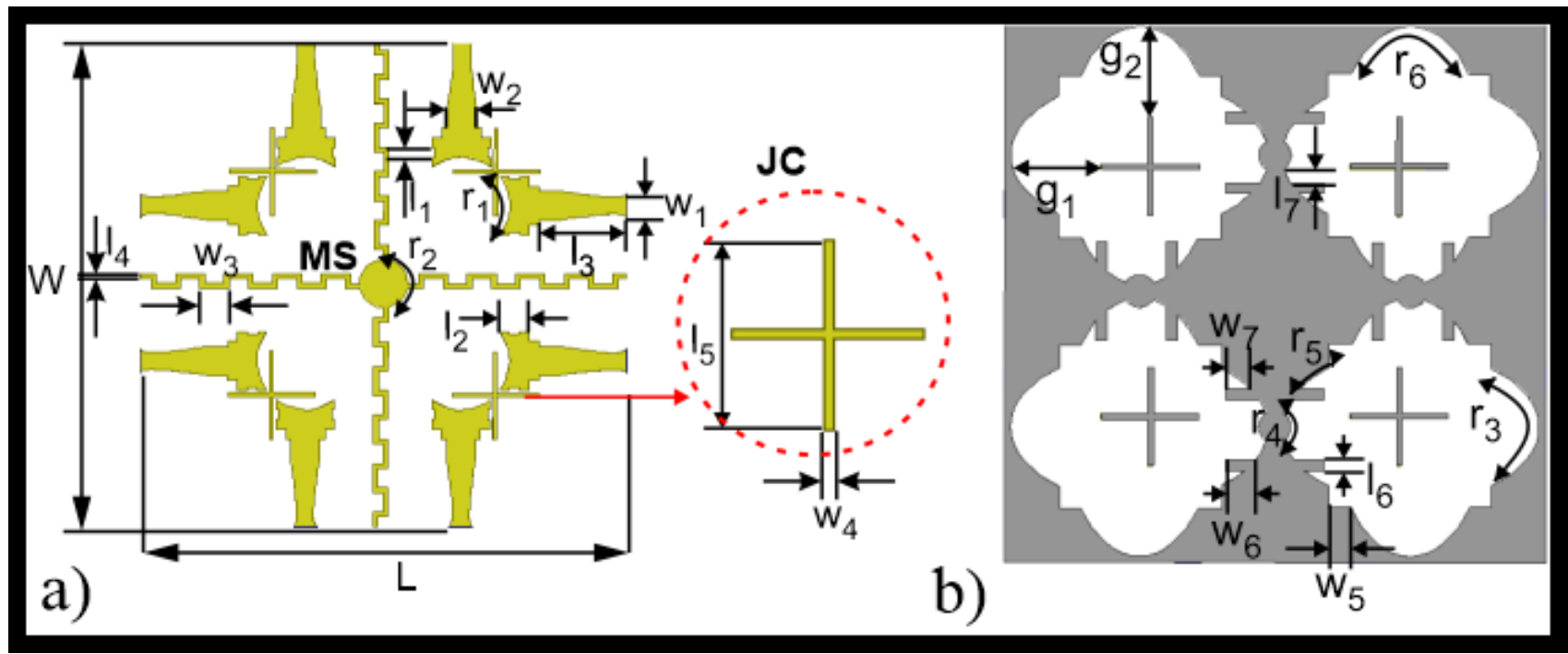

Figure 2. Design of proposed MIMO: (a) front view; (b) back view.

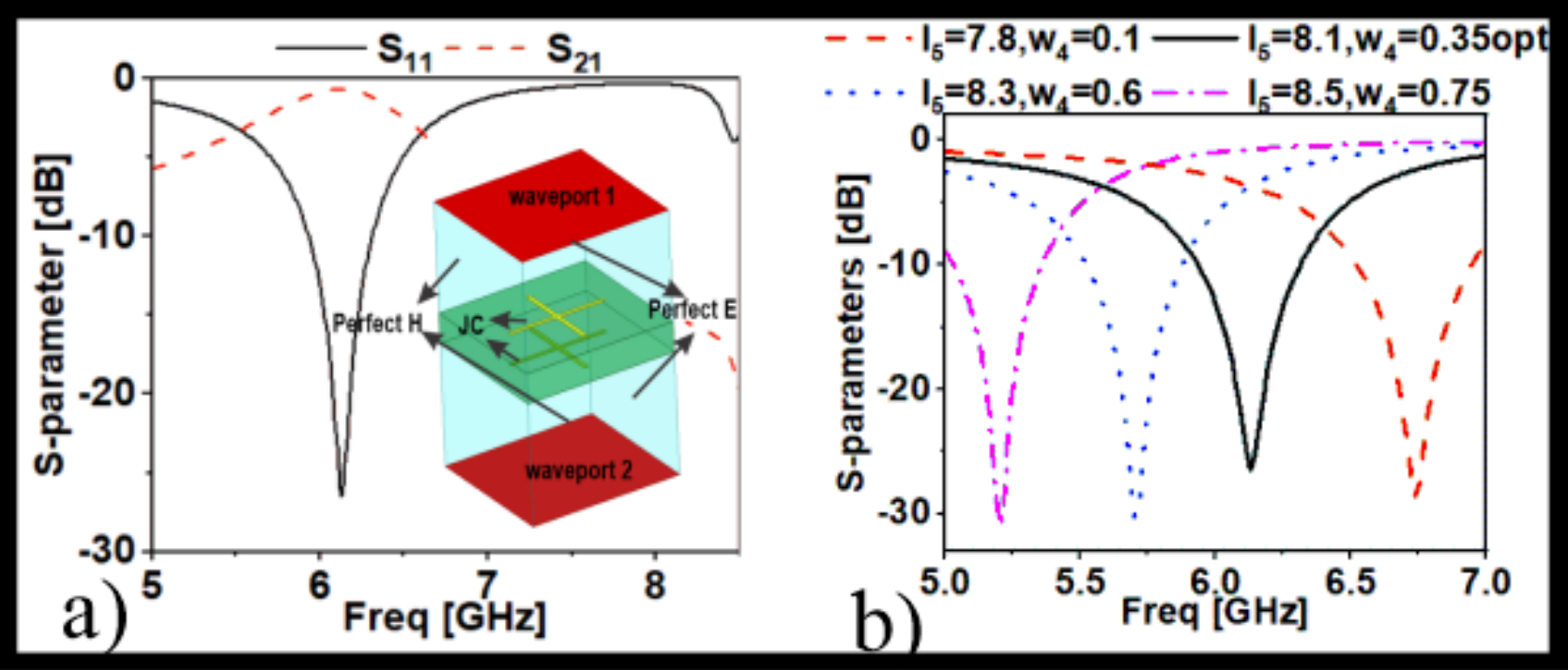

Figure 3. FSS-based JC: (a) analysis; (b) parametric variation.

\section{Simulation and Measurements}

The proposed MIMO system was fabricated over a $1.6 \mathrm{~mm}$ thick FR-4 laminate through a milling machine once optimizations were completed. The off-body scattering parameters and radiation characteristics were measured using an Agilent N5227A vector network analzser (VNA) in a SATIMO measurement setup at UKM-star lab, as shown in Figure 4a. Moreover, on-body measurements were performed by placing the fabricated antenna array on the human body, as illustrated in Figure $4 \mathrm{~b}$. Owing to the two-port measurement setup, multiport measurements were performed by enabling two ports and terminating all other ports with $50 \Omega$ matched loads. The measurements were performed for side-byside (ant. 2,3) orthogonal (ant. 3,4), and across (ant 3,6) configurations of the fabricated prototype. The simulated vs. measured performance is presented below. 


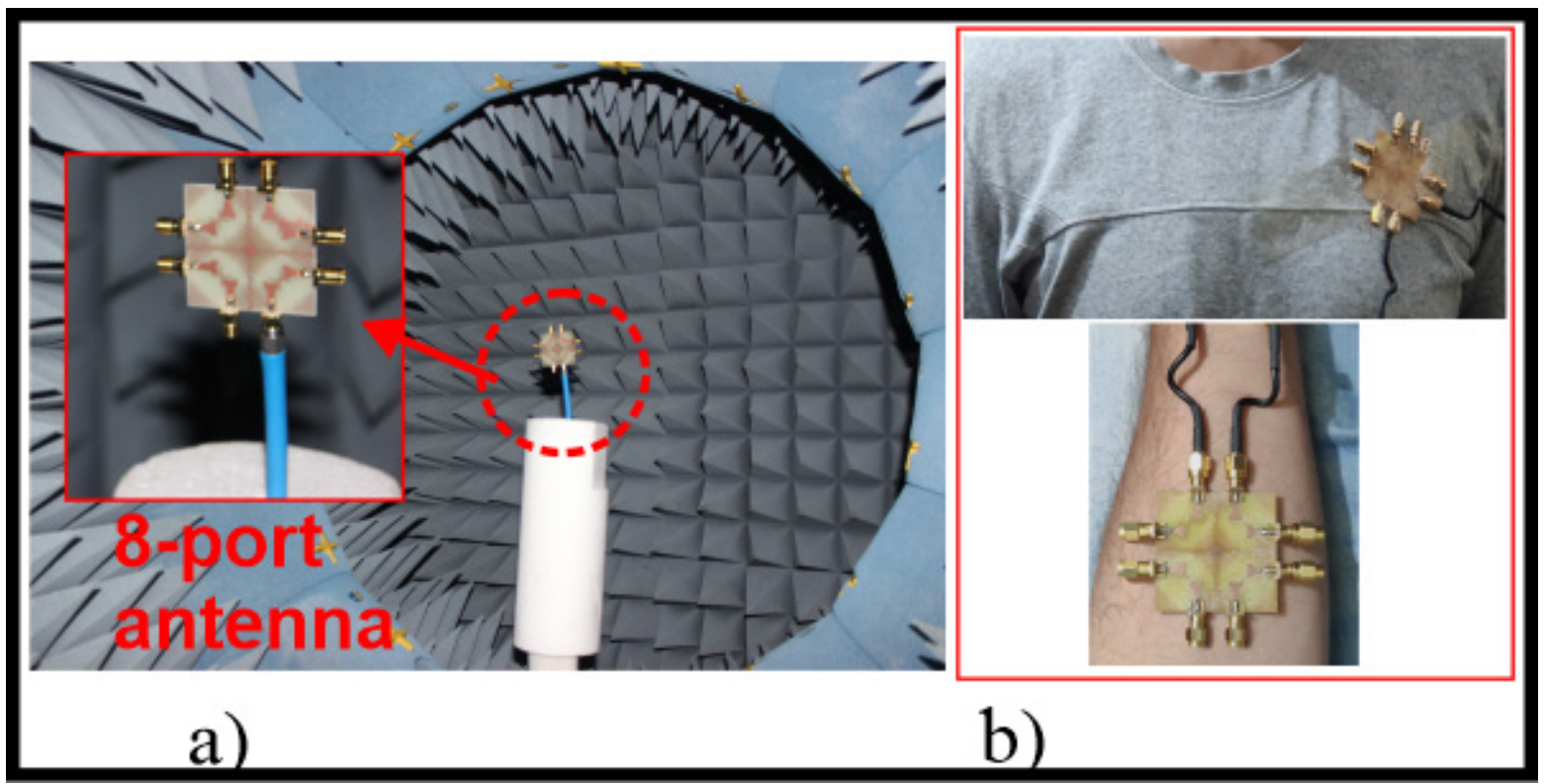

Figure 4. Measurements of the proposed MIMO antenna array: (a) free space; (b) on-body.

\subsection{S-Parameters}

The simulated and measured S-parameters are illustrated in Figure 5. As shown in Figure 5a, the proposed MIMO offered wideband impedance matching, i.e., $3 \mathrm{GHz}$ to 10.6 GHz. However, after the introduction of lossy decoupling mechanisms, the impedance bandwidth was slightly reduced. In addition, the $\mathrm{OB}$ performance of this system also revealed a reduction in impedance matching and a slight shifting of resonances; however, overall, the proposed MIMO system achieved $111 \%$ and $110 \%$ fractional bandwidth (FBW) in off- and on-body scenarios.

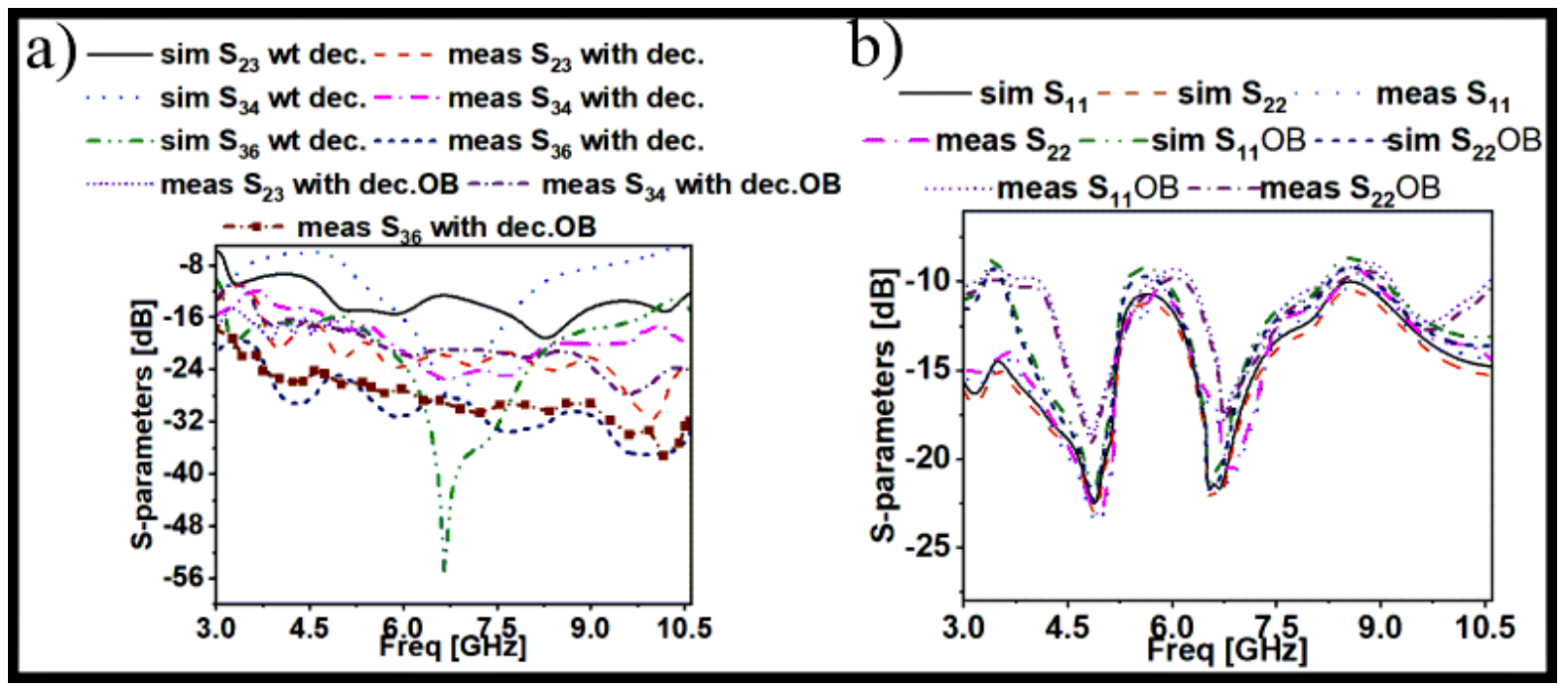

Figure 5. Simulated vs. measured S-parameters: (a) isolation; (b) return losses.

The proposed MS and FSS-based JC provided isolation in all configurations including side-by-side, orthogonal, and across. The off- and on-body results with and without decoupling are presented in Figure 5b. The results reveal that MS achieved $20 \mathrm{~dB}$ and $27 \mathrm{~dB}$ isolations in side-by-side and across placed antennas, respectively, for off- and on-body. Notably, the JC also provided isolation of no less than $20 \mathrm{~dB}$ in the orthogonal configuration for both off- and on-body. 


\subsection{Surface Current Distributions}

The surface current distributions (j-surf) at $3.5 \mathrm{GHz}$ and $5 \mathrm{GHz}$ are presented in Figure $6 \mathrm{a}, \mathrm{b}$, respectively. These current distributions were carried out with proposed decoupling mechanisms to highlight their effectiveness. The surface currents had a more pronounced effect on feeding, shared ground plane, and decoupling structures. The JC was optimized in a way that it did not couple with the main radiation element to maintain the overall compactness of the system.

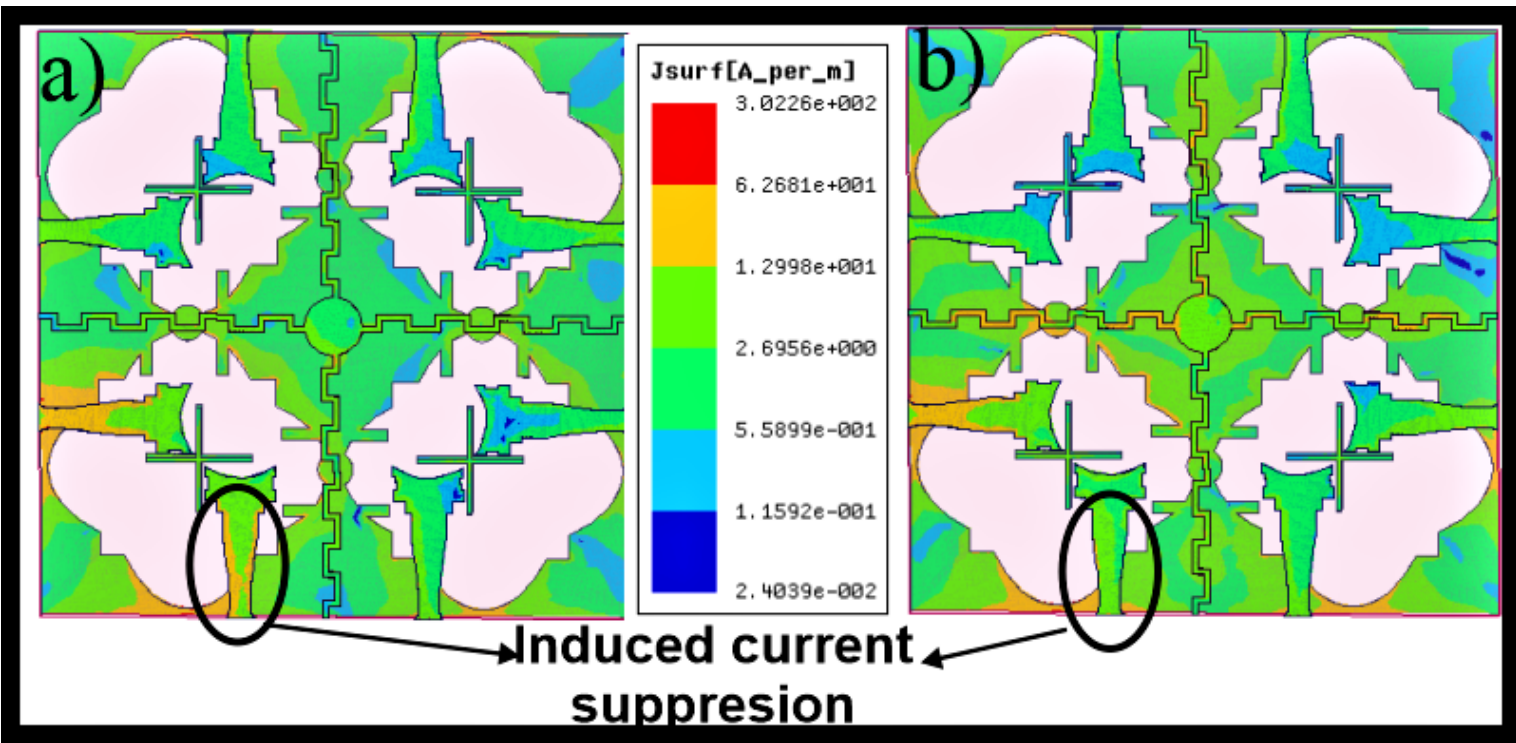

Figure 6. J-surf: (a) $3.5 \mathrm{GHz}$; (b) $5 \mathrm{GHz}$.

\subsection{Radiation Characteristics}

The off- and on-body radiation performance of the finalized proposed antenna system in array topology was investigated at $3.5 \mathrm{GHz}, 5 \mathrm{GHz}$, and $7.5 \mathrm{GHz}$. The off- and on-body measured far-field evaluations were performed in terms of principle E- and H-planes, as shown in Figure 7a,b, respectively. The results showed some distortion as fabrication imperfections and OB implementation led to some pattern distortion. However, off- and on-body 3D radiation patterns in Figure 8 confirmed nearly an omnidirectional behavior due to square-shaped grounds of the proposed symmetrical patches. In addition to this, the off-body simulated radiation performance of a single-antenna element was also evaluated at the mentioned frequencies. The 3D radiation performance in Figure 9 also revealed an omnidirectional response having at least $4.5 \mathrm{dBi}$ gain.

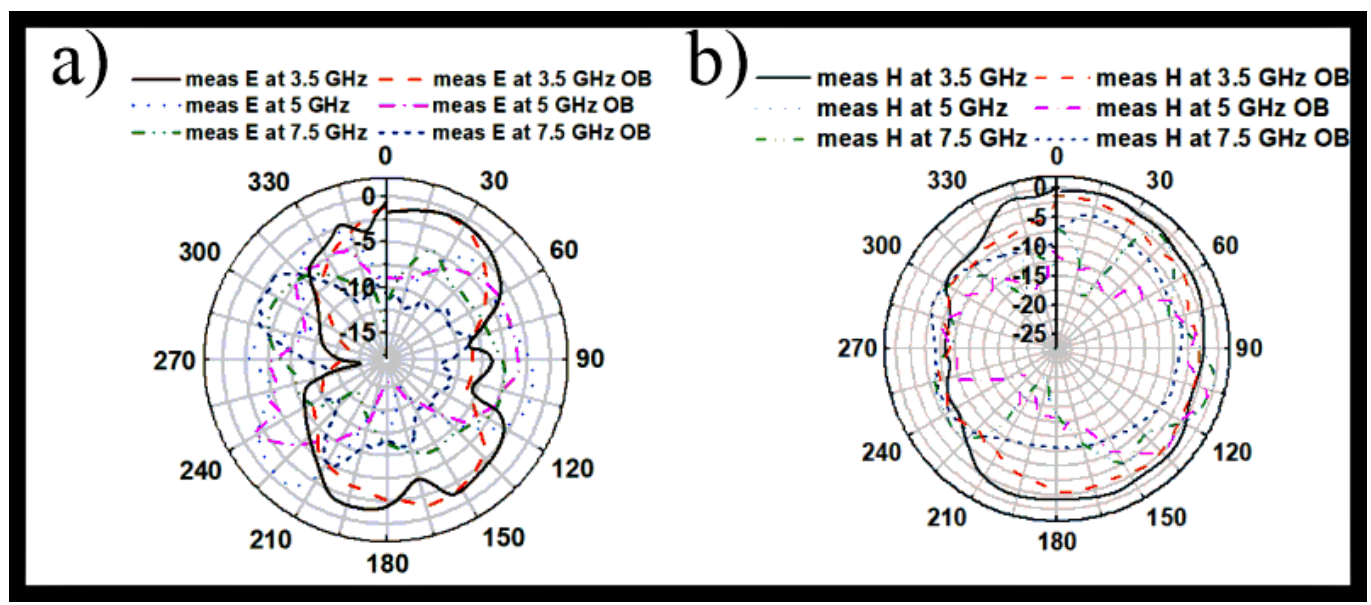

Figure 7. Radiation patterns: (a) E-plane; (b) H-plane. 

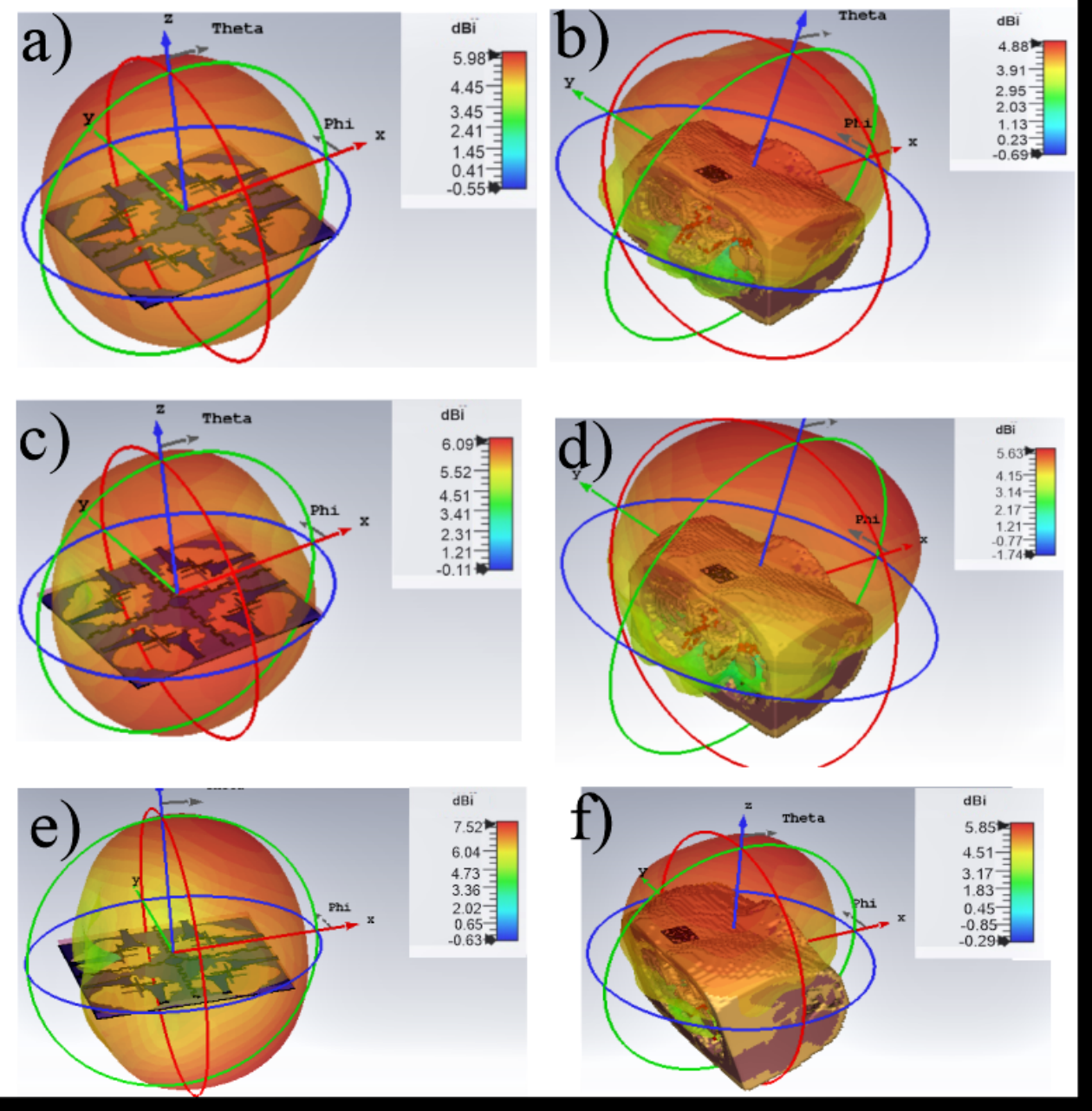

Figure 8. 3D Radiation patterns: (a) $3.5 \mathrm{GHz}$; (c) $5 \mathrm{GHz}$; (e) $7.5 \mathrm{GHz}$; (b) $3.5 \mathrm{GHz} \mathrm{OB}$; (d) $5 \mathrm{GHz} \mathrm{OB}$; (f) $7.5 \mathrm{GHz} \mathrm{OB}$.

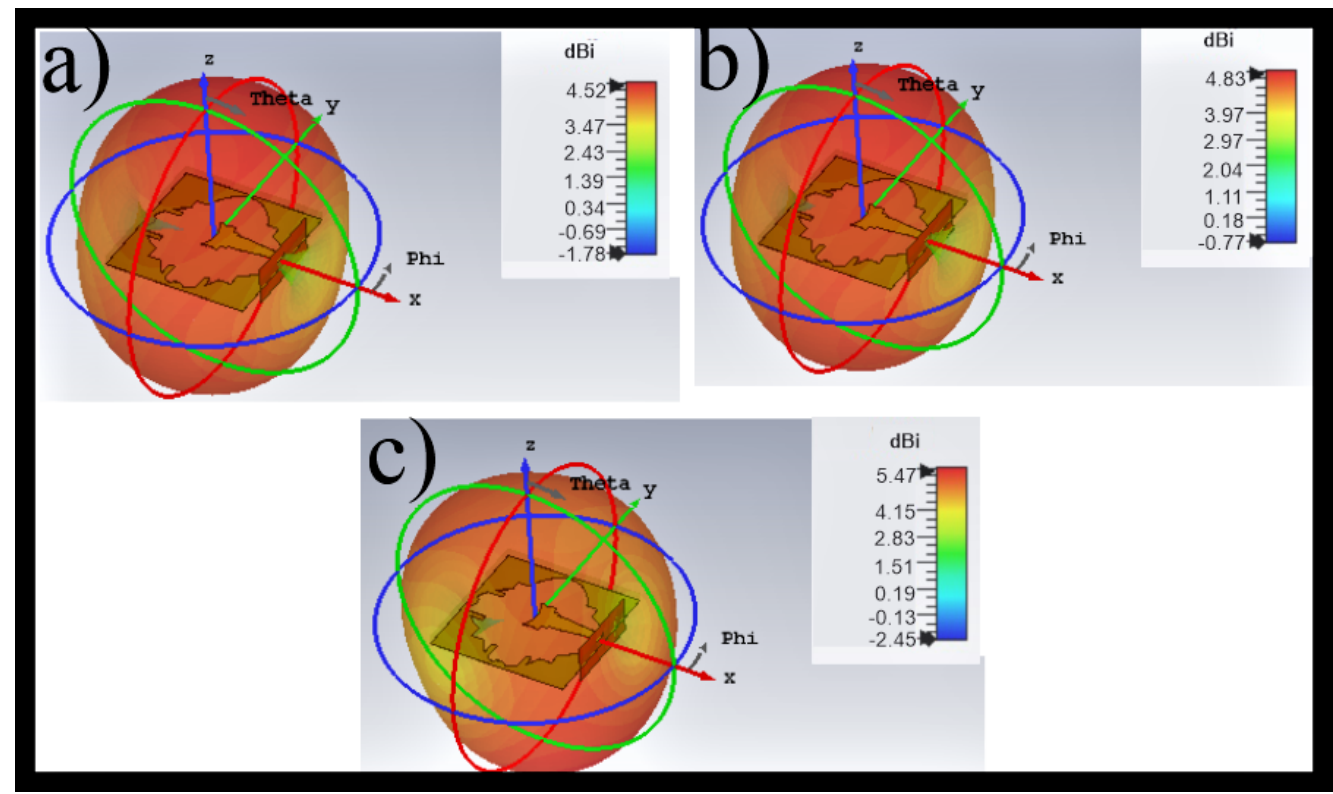

Figure 9. 3D Radiation patterns of single antenna: (a) $3.5 \mathrm{GHz}$; (b) $5 \mathrm{GHz}$; (c) $7.5 \mathrm{GHz}$. 


\subsection{Diversity Performance}

The envelope correlation coefficient (ECC), channel capacity loss (CCL), total active reflection coefficient (TARC), and diversity gain (DG) were investigated to determine the diversity performance of the proposed MIMO off- and on-body. It may be inferred from the literature [29] that ECC and CCL should be less than 0.5, while TARC and DG should be less than $0 \mathrm{~dB}$ and $9-10 \mathrm{~dB}$, respectively. Equations (1)-(4) were used to evaluate these parameters [30-34].

$$
\begin{gathered}
\rho_{e}=\frac{\left|\iint_{4 \pi}\left[\vec{E}_{i}(\theta, \phi) \times \vec{E}_{j}(\theta, \phi)\right] d \Omega\right|^{2}}{\iint_{4 \pi}\left|\vec{E}_{i}(\theta, \varphi)\right|^{2} d \Omega \iint_{4 \pi}\left|\vec{E}_{j}(\theta, \varphi)\right|^{2} d \Omega} . \\
\mathrm{C}(\text { loss })=-\log _{2}\left(\operatorname{det} \psi^{R}\right)
\end{gathered}
$$

where

$$
\psi^{R}=\left[\begin{array}{ll}
\rho_{11} & \rho_{12} \\
\rho_{21} & \rho_{22}
\end{array}\right], \rho_{i i}=1-\left(\left|S_{i i}\right|^{2}+\left|S_{i j}\right|^{2}\right),
$$

and

$$
\begin{gathered}
\rho_{i j}=-\left(S_{i i}^{*} S_{i j}+S^{*}{ }_{j i} S_{i j}\right) \text { for } i j=1 \text { or } 2 . \\
\text { TARC }=\sqrt{\frac{\left|\sum_{n=8} S_{1 n}\right|^{2}+\cdots+\left|\sum_{n=8} S_{8 n}\right|^{2}}{8} .} \\
\text { DG }=10 \sqrt{1-\left|\rho_{e}\right|^{2}} .
\end{gathered}
$$

Each parameter was evaluated for all configurations including side-by-side, orthogonal, and across for this system, as depicted in Figure 9a-d. Overall, the proposed design achieved ECC $<0.17, \mathrm{CCL}<0.3$, TARC $<-13 \mathrm{~dB}$, and DG $>9.92 \mathrm{~dB}$ in all configurations.

The simulated and measured results of the gain and efficiency of the proposed MIMO system are presented in Figure 10. Figure 11 demonstrates that both simulations and measurements of gain and efficiency were in line. It may be inferred from the results that gain varied by $5-7 \mathrm{dBi}$ and $3.5-5 \mathrm{dBi}$ for off-body and on-body, respectively. Notably, the radiation efficiency varied $75-85 \%$ in the off-body scenario with a slight reduction in efficiency in contrast to $70-78 \%$ for on-body. The reduction in measured gain and radiation efficiency was primarily due to on-body placement, the lossy nature of FR-4, and fabrication imperfections. However, the optimum MIMO performance, return loss, and isolations at a slight cost of gain and efficiency may be perceived as acceptable.

\subsection{On-Body SAR Analysis}

The specific absorption rate refers to the backward electromagnetic radiation of an antenna element absorbed by human tissue when placed in close contact. These radiations may increase the temperature of tissues to an unhealthy limit. The regularity authorities FCC, IEEE, and ICNIRP standardized the SAR for wearer safety [12].

The specific absorption rate (SAR) was evaluated by mounting the antenna array at a $5 \mathrm{~mm}$ gap on the ribcage, right arm, and thigh of the CST's human anatomical voxel model. The SAR analysis was performed at frequencies $3.5 \mathrm{GHz}$ and $5 \mathrm{GHz}$, as shown in Figure 12a-f. These values were evaluated according to the IEEE C95.1-2005 standards for all three positions. Most of the devices operating in close contact with the human body typically utilized little power in the $\mathrm{mW}$ ranges. Hence, $10 \mathrm{~g}$ peak SAR values were noted for $500 \mathrm{~mW}$ of input power. The results reveal that these SAR values were in safer limits (below $2 \mathrm{~W} / \mathrm{Kg}$ ) for the prescribed input power at desired frequencies. 


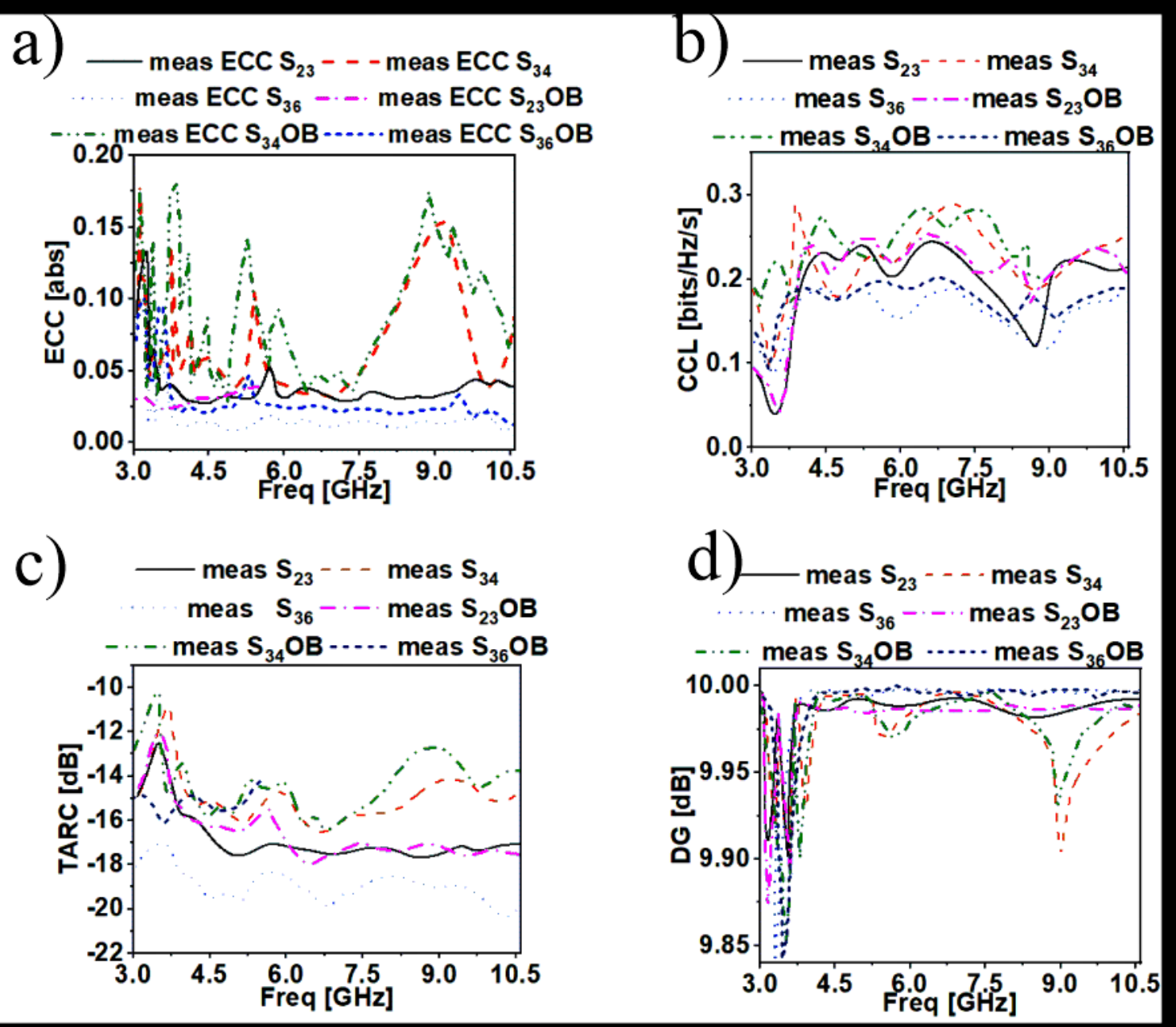

Figure 10. MIMO performance parameters: (a) CCL; (b) TARC; (c) ECC; (d) DG.
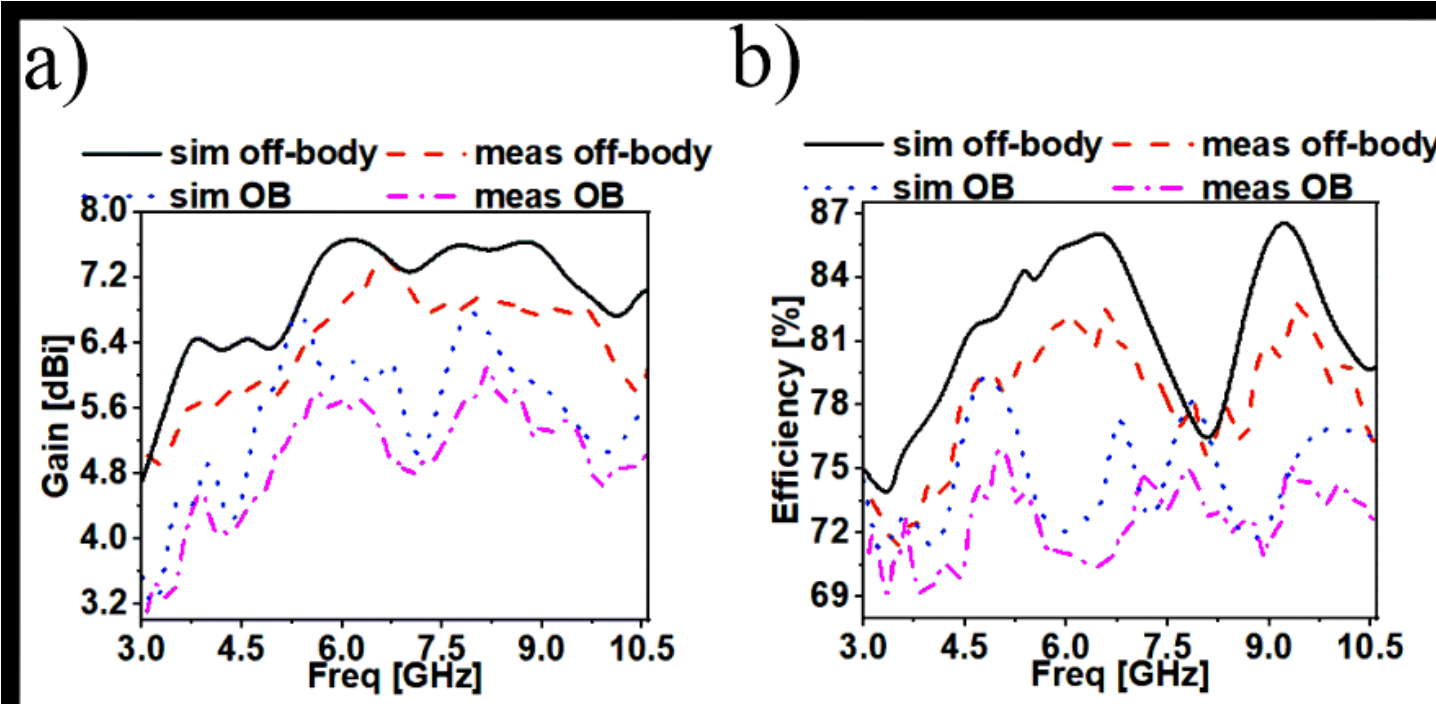

Figure 11. Simulations vs. measurements: (a) gain; (b) efficiency. 

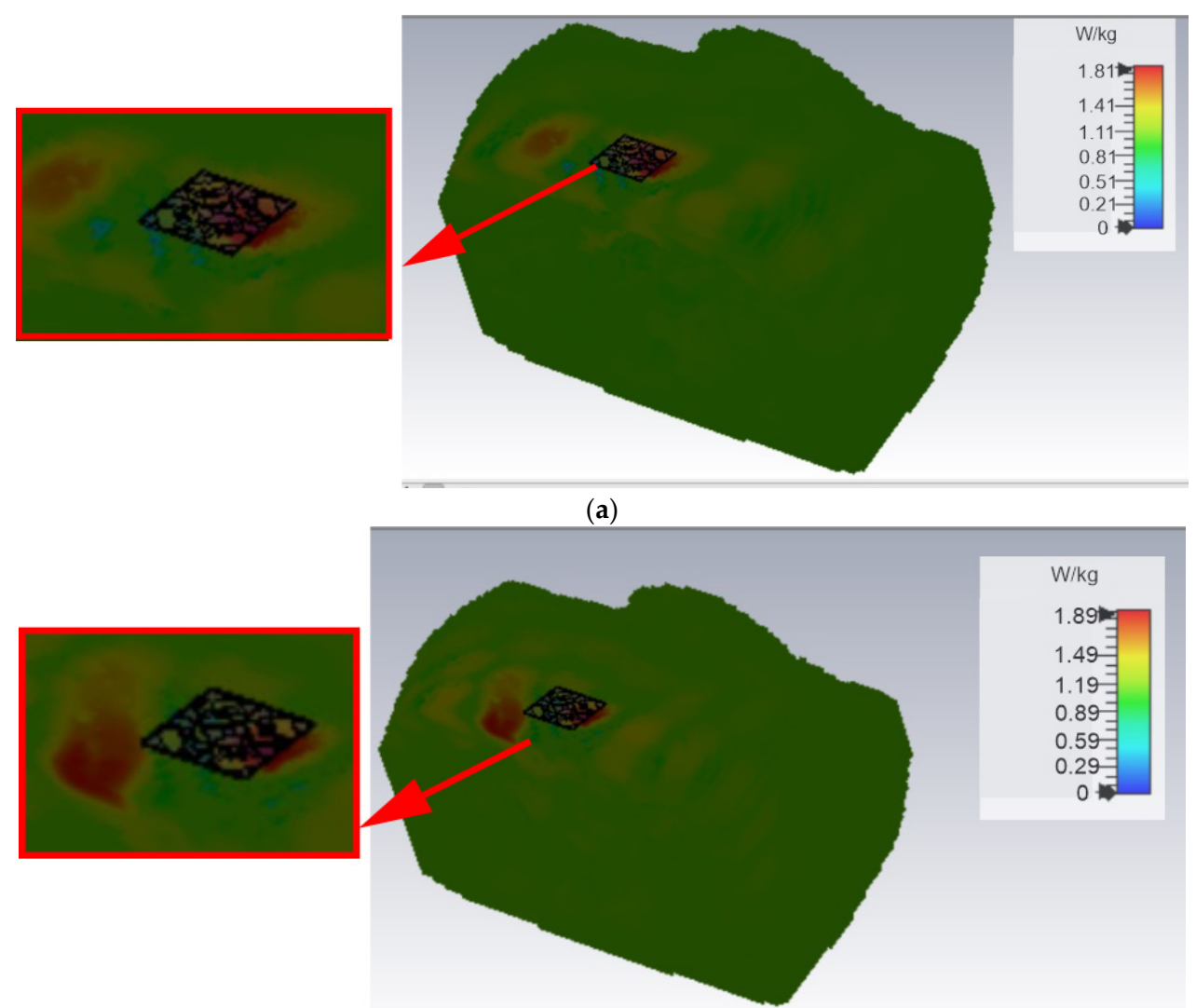

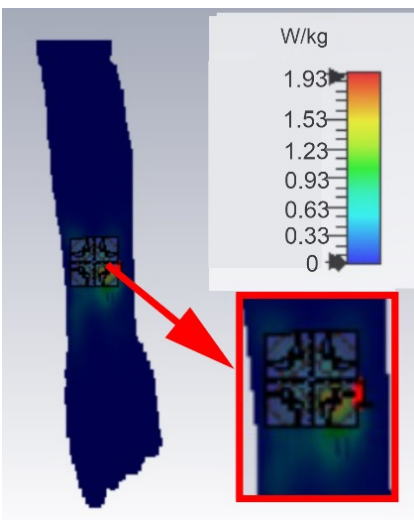

(c)

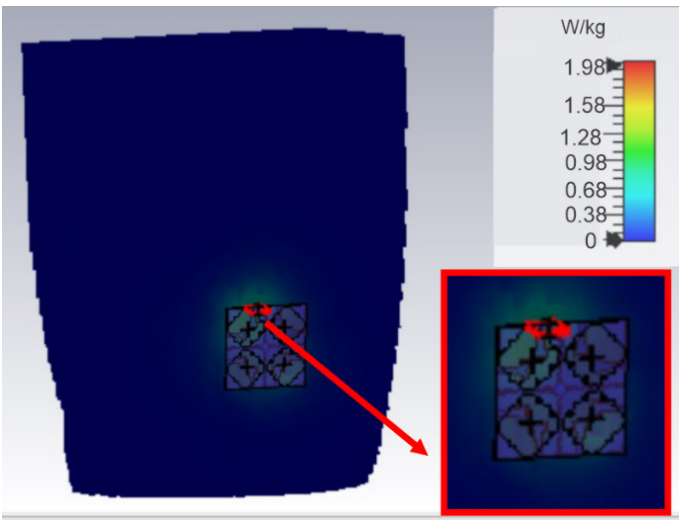

(e) (b)

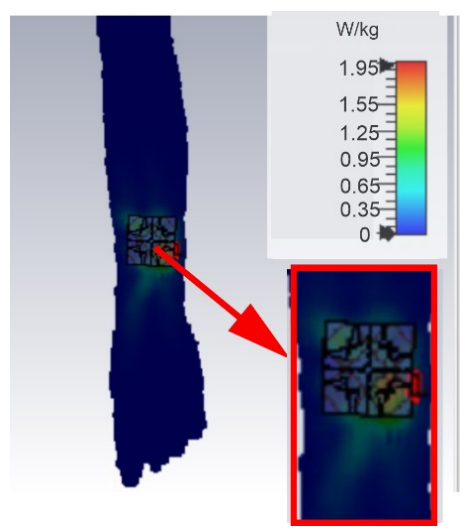

(d)

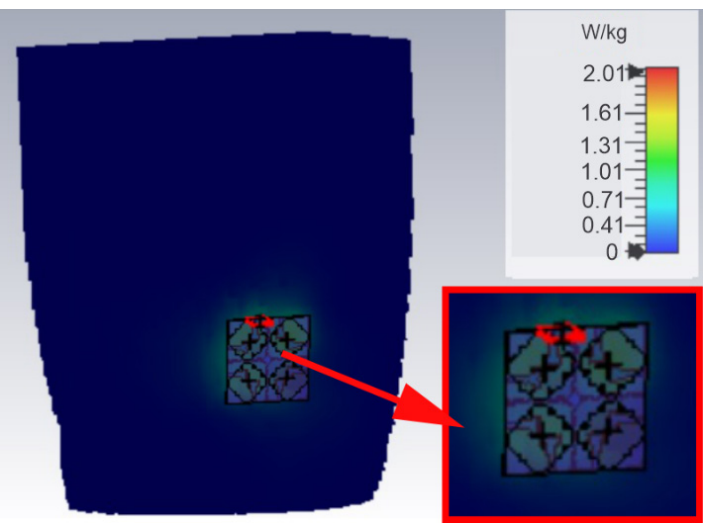

(f)

Figure 12. SAR analysis: (a,b) ribcage at $3.5 \mathrm{GHz}$ and $5 \mathrm{GHz} ;(\mathbf{c}, \mathbf{d})$ arm at $3.5 \mathrm{GHz}$ and $5 \mathrm{GHz}$; $(\mathbf{e}, \mathbf{f})$ leg at $3.5 \mathrm{GHz}$ and $5 \mathrm{GHz}$. 


\section{Comparison with Existing Literature}

A detailed comparison with closely related work is presented in Table 2 to highlight the novelty and features of the proposed MIMO system. The performance metrics include size, number of ports, FBW off/on body, ECC, CCL, TARC, and DG. It is clear from the comparative analysis that the proposed MIMO system achieved higher bandwidth with improved isolation, acceptable MIMO performance, and SAR ranges over fewer complex configurations. It is also worth mentioning that this system comprised eightantenna elements arranged in a simple planar form with a small footprint, suitable for high-bandwidth WBAN telemetry applications and was highly competitive as compared to the existing systems.

Table 2. Comparative analysis.

\begin{tabular}{|c|c|c|c|c|c|c|c|c|}
\hline Ref. & Size (mm) & No. of Ports & FBW Off-Body & FBW On-Body & ECC (abs) & CCL & TARC & DG \\
\hline [12] & $40 \times 40$ & 4 & 92 & 91 & $<0.23$ & 0.13 & - & $<9.7$ \\
\hline [21] & 20 radii & 6 & 13 & 13 & $<0.06$ & - & - & - \\
\hline [35] & $35 \times 55$ & 2 & 127 & - & $<0.02$ & 0.13 & - & $>9.9$ \\
\hline [36] & $150 \times 85$ & 2 & 3.3 & 3.2 & 0.05 & - & - & - \\
\hline [37] & 19 radii & 2 & 27 & 30 & 0.13 & - & - & - \\
\hline [38] & $55 \times 40$ & 2 & 45 & 46 & 0.02 & $<9.7$ & - & - \\
\hline [39] & $26 \times 26$ & 4 & 58 & 33 & 0.02 & 0.3 & - & 9.91 \\
\hline [40] & $59 \times 29$ & 2 & - & - & 0.05 & - & - & 9.95 \\
\hline [41] & 15.5 radii & 3 & 40 & 40 & $<0.01$ & - & - & - \\
\hline [42] & $9 \times 50$ & 4 & 27 & 26 & $<0.025$ & - & - & - \\
\hline [43] & $5 \times 35$ & 2 & 153.5 & 152 & 0.039 & 0.4 & -10 & 9.9 \\
\hline [44] & $48 \times 90$ & 2 & 122 & 120 & 0.1 & - & - & 9.9 \\
\hline This work & $45 \times 45$ & 8 & 111 & 110 & $<0.17$ & $<0.4$ & $<-13$ & 9.92 \\
\hline
\end{tabular}

\section{Conclusions}

In this work, a compact wideband MIMO antenna system for on-body WBAN devices was presented. The proposed MIMO system comprised eight identical antenna elements organized in three different configurations, i.e., side-by-side, orthogonal, and across. An overall, $111 \%$ and $110 \%$ wide fractional bandwidth was achieved for off- and on-body scenarios. However, an isolation of no less than $20 \mathrm{~dB}$ for all configurations was achieved. More importantly, off- and on-body MIMO performance parameters including ECC, CCL, TARC, and DG were well within acceptable limits. To ensure safety for on-body usage of the proposed system, the evaluated SAR was found to be within tolerable limits, i.e., input power $<500 \mathrm{~mW}$, assuring its suitability for on-body WBAN telemetry applications such as performance trackers for heart failure detection and glucose sensors.

There were a few limiting factors to the proposed work, the improvements of which may further increase performance and suitability in future studies. Although the employed FR-4 is low-cost and readily available, owing to its lossy nature, impedance matching and SAR may be further improved by employing more sophisticated laminates. The proposed system has a planar design profile which might require special design adjustments for ultracompact devices; thus, a flexible design profile is more desirable for such scenarios. In addition, a number of radiation elements can be increased to meet higher-date-rate requirements.

Author Contributions: M.B., conceptualization, formal analysis, funding acquisition, methodology, software, supervision, and writing-review and editing; S.S., conceptualization, data curation, formal analysis, investigation, methodology, visualization, and writing-original draft; Y.K., resources and project administration; Z.R., formal analysis, software, and writing-review and editing; R.A.W., project administration; M.A.B., S.N.K. and N.L.K., funding acquisition and writing-review and editing. All authors read and agreed to the published version of the manuscript. 
Funding: The research was supported by the Ministry of Science and Higher Education of the Russian Federation in financing of new laboratories under the guidance of young scientists within the framework of the national project "Science and Universities" (project FSSS-2021-0016) in the section of numerical calculations and under the FSRC "Crystallography and Photonics" of the Russian Academy of Sciences (the state task No. 007-GZ/Ch3363/26) in the section of theoretical analysis.

Acknowledgments: This work was supported by ORIC Balochistan under large-scale Project07/Research Projects GoB/BUITEMS/2021/06.

Conflicts of Interest: The authors declare no conflict of interest.

\section{References}

1. Hall, P.S.; Hao, Y. Antennas and Propagation for Body-Centric Wireless Communications; Artech House: London, UK, 2012.

2. Pellegrini, A. Antennas and propagation for body-centric wireless communications at millimeter-wave frequencies: A review [wireless corner]. IEEE Antennas Propag. Mag. 2013, 55, 262-287. [CrossRef]

3. Mahmood, S.N.; Ishak, A.J.; Ismail, A.; Soh, A.C.; Zakaria, Z.; Alani, S. ON-OFF Body Ultra-wideband (UWB) Antenna for Wireless Body Area Networks (WBAN): A Review. IEEE Access 2020, 8, 150844-150863. [CrossRef]

4. Khajeh-Khalili, F. A broadband all-textile wearable MIMO antenna for wireless telecommunication/medical applications. J. Text. Inst. 2021, 112, 2013-2020. [CrossRef]

5. Jeong, W.; Tak, J.; Choi, J. A low-profile IR-UWB antenna with ring patch for WBAN applications. IEEE Antennas Wirel. Propag. Lett. 2015, 14, 1447-1450. [CrossRef]

6. Li, E.; Li, X.J.; Seet, B.-C. A Triband Slot Patch Antenna for Conformal and Wearable Applications. Electronics 2021, $10,3155$. [CrossRef]

7. Smith, D.B.; Miniutti, D.; Lamahewa, T.A.; Hanlen, L.W. Propagation models for body-area networks: A survey and new outlook IEEE Antennas Propag. Mag. 2013, 55, 97-117. [CrossRef]

8. Mahmood, S.N.; Ishak, A.J.; Jalal, A.; Saeidi, T.; Shafie, S.; Soh, A.C.; Imran, M.A.; Abbasi, Q.H. A Bra Monitoring System Using a Miniaturized Wearable Ultra-Wideband MIMO Antenna for Breast Cancer Imaging. Electronics 2021, 10, 2563. [CrossRef]

9. See, T.S.; Chen, Z.N.; Qing, X.M. Proximity effect of UWB antenna on human body. In Proceedings of the Asia Pacific Microwave Conference 2009, Singapore, 7-10 December 2009; pp. 2192-2195.

10. See, T.S.; Chen, Z.N. Experimental characterization of UWB antennas for on-body communications. IEEE Trans. Antennas Propag. 2009, 57, 866-874. [CrossRef]

11. Zu, H.; Wu, B.; Yang, P.; Li, W.; Liu, J. Wideband and High-Gain Wearable Antenna Array with Specific Absorption Rate Suppression. Electronics 2021, 10, 2056. [CrossRef]

12. Iqbal, A.; Smida, A.; Alazemi, A.J.; Waly, M.I.; Mallat, N.K.; Kim, S. Wideband circularly polarized MIMO antenna for high data wearable biotelemetric devices. IEEE Access 2020, 8, 17935-17944. [CrossRef]

13. Yang, D.; Hu, J.; Liu, S. A low profile UWB antenna for WBAN applications. IEEE Access 2018, 6, 25214-25219. [CrossRef]

14. Sambandam, P. Compact monopole antenna backed with fork slotted EBG for wearable applications. IEEE Antennas Wirel. Propag. Lett. 2019, 19, 228-232. [CrossRef]

15. Särestöniemi, M.; Pomalaza-Ráez, C.; Kissi, C.; Berg, M.; Hämäläinen, M.; Iinatti, J. WBAN channel characteristics between capsule endoscope and receiving directive UWB on-body antennas. IEEE Access 2020, 8, 55953-55968. [CrossRef]

16. Le, T.T.; Kim, Y.D.; Yun, T.Y. A Triple-Band Dual-Open-Ring High-Gain High-Efficiency Antenna for Wearable Applications. IEEE Access 2021, 9, 118435-118442. [CrossRef]

17. Smida, A.; Iqbal, A.; Alazemi, A.J.; Waly, M.I.; Ghayoula, R.; Kim, S. Wideband wearable antenna for biomedical telemetry applications. IEEE Access 2020, 8, 15687-15694. [CrossRef]

18. Gupta, A.; Kansal, A.; Chawla, P. Design and performance analysis of L-shaped ground and radiator antenna with a metallic reflector for WBAN. Int. J. Electron. 2021, 108, 623-635. [CrossRef]

19. Le, T.T.; Yun, T.Y. Miniaturization of a dual-band wearable antenna for WBAN applications. IEEE Antennas Wirel. Propag. Lett. 2020, 19, 1452-1456. [CrossRef]

20. Wang, C.; Zhang, L.; Wu, S.; Huang, S.; Liu, C.; Wu, X. A Dual-band Monopole Antenna with EBG for Wearable Wireless Body Area Networks. Appl. Comput. Electromagn. Soc. J. 2021, 36, 48-54. [CrossRef]

21. Kanagasabai, M.; Sambandam, P.; Alsath, M.G.N.; Palaniswamy, S.; Ravichandran, A.; Girinathan, C. Miniaturized Circularly Polarized UWB Antenna for Body Centric Communication. IEEE Trans. Antennas Propag. 2021, 70, 189-196. [CrossRef]

22. Kumar, S. Wideband Circularly Polarized Textile MIMO Antenna for Wearable Applications. IEEE Access 2021, 9, 108601-108613. [CrossRef]

23. Jiang, Z. Wideband Loop Antenna with Split-Ring Resonators for Wireless Medical Telemetry. IEEE Antennas Wirel. Propag. Lett. 2019, 18, 1415-1419. [CrossRef]

24. Agarwal, P.; Deniz, S.; Jain, S.; Alderremy, A.A.; Aly, S. A new analysis of a partial differential equation arising in biology and population genetics via semi analytical techniques. Phys. A Stat. Mech. Its Appl. 2020, 54, 122769. [CrossRef]

25. Singh, K. Design of rectangular microstrip patch antenna based on Artificial Neural Network algorithm. In Proceedings of the 2nd International Conference on Signal Processing and Integrated Networks (SPIN), Noida, India, 19-20 February 2015. 
26. Goudah, M.; Yousef, M.Y. Bandwidth Enhancement Techniques Comparison for Ultra Wideband Microstrip Antennas for Wireless Application. J. Theor. Appl. Inf. Technol. 2012, 35, 184-193.

27. Hammerstad, E.; Jensen, O. Accurate models for microstrip computer-aided design. In Proceedings of the 1980 IEEE MTT-S International Microwave Symposium Digest, Washington, DC, USA, 28-30 May 1980; pp. 407-409. [CrossRef]

28. Munk, B.A. Frequency Selective Surfaces: Theory and Design; Wiley: Hoboken, NJ, USA, 2000.

29. Shakir, S. A Compact 8-Element 3D UWB Diversity Antenna System for Off Device Installation. IEEE Access 2021, 9, 44117-44127. [CrossRef]

30. Wang, Z.; Li, C.; Wu, Q.; Yin, Y. A metasurface-based low-profile array decoupling technology to enhance isolation in MIMO antenna systems. IEEE Access 2020, 8, 125565-125575. [CrossRef]

31. Shin, H.; Lee, J.H. Capacity of multiple-antenna fading channels: Spatial fading correlation, double scattering, and keyhole. IEEE Trans. Inf. Theory 2003, 49, 2636-2647. [CrossRef]

32. Jaglan, N.; Gupta, S.D. Design and analysis of performance enhanced microstrip patch antenna with EBG substrate. Int. J. Microw. Opt. Technol. 2015, 10, 79-88.

33. Bait-Suwailam, M.M.; Boybay, M.S.; Ramahi, O.M. Electromagnetic coupling reduction in high-profile monopole antennas using single-negative magnetic metamaterials for MIMO applications. IEEE Trans. Antennas Propag. 2010, 58, 2894-2902. [CrossRef]

34. Glazunov, A.A.; Molisch, A.F.; Tufvesson, F. Mean effective gain of antennas in a wireless channel. IET Microw. Antennas Propag. 2009, 3, 214-227. [CrossRef]

35. Biswas, A.K.; Chakraborty, U. Compact wearable MIMO antenna with improved port isolation for ultra-wideband applications. IET Microw. Antennas Propag. 2019, 13, 498504.

36. Zhang, J.; Yan, S.; Hu, X.; Vandenbosch, G.A.E. Mutual Coupling Suppression for On-Body Multiantenna Systems. IEEE Trans. Electromagn. Compat. 2020, 62, 1045-1054. [CrossRef]

37. Wang, B.; Yan, S. Design of Smartwatch Integrated Antenna with Polarization Diversity. IEEE Access 2020, 8, 123440-123448. [CrossRef]

38. Wang, Y.Y.; Ban, Y.L.; Nie, Z.; Sim, C.Y.D. Dual-Loop Antenna for 4G LTE MIMO Smart Glasses Applications. IEEE Antennas Wirel. Propag. Lett. 2019, 18, 1818-1822. [CrossRef]

39. Elfergani, I.; Iqbal, A.; Zebiri, C.; Basir, A.; Rodriguez, J.; Sajedin, M.; Pereira, A.D.; Mshwat, W.; Alhameed, R.A.; Ullah, S. Low-Profile and Closely Spaced Four-Element MIMO Antenna for Wireless Body Area Networks. Electronics 2020, 9, 258. [CrossRef]

40. Du, C.; Wang, X.; Jin, G.Y. A Compact Tri-Band Flexible MIMO Antenna Based on Liquid Crystal Polymer for Wearable Applications. Prog. Electromagn. Res. 2021, 102, 217-232. [CrossRef]

41. Zhang, K.; Jiang, Z.H.; Hong, W.; Werner, D.H. A Low-Profile and Wideband Triple-Mode Antenna for Wireless Body Area Network Concurrent On-/Off-Body Communications. IEEE Trans. Antennas Propag. 2020, 68, 1982-1994. [CrossRef]

42. Chung, M.-A.; Hsiao, C.-W.; Yang, C.-W.; Chuang, B.-R. $4 \times 4$ MIMO Antenna System for Smart Eyewear in Wi-Fi 5G and Wi-Fi 6e Wireless Communication Applications. Electronics 2021, 10, 2936. [CrossRef]

43. Dey, A.B.; Pattanayak, S.S.; Mitra, D.; Arif, W. Investigation and design of enhanced decoupled UWB MIMO antenna for wearable applications. Microw. Opt. Technol. Lett. 2021, 63, 845-861. [CrossRef]

44. Soumendu, G.; Sourav, R.; Ujjal, C.; Abhishek, S. An ELC meta-resonator inspired wideband wearable MIMO antenna system for biotelemetry applications. J. Electromagn. Waves Appl. 2021, 1-17. [CrossRef] 